\title{
Synthesis, optimization, and characterization of silver nanoparticles from Acinetobacter calcoaceticus and their enhanced antibacterial activity when combined with antibiotics
}

\author{
This article was published in the following Dove Press journal: \\ International Journal of Nanomedicine \\ 5 November 2013 \\ Number of times this article has been viewed
}

\author{
Richa Singh' \\ Priyanka Wagh' \\ Sweety Wadhwani' \\ Sharvari Gaidhani ${ }^{2}$ \\ Avinash Kumbhar ${ }^{3}$ \\ Jayesh Bellare ${ }^{4}$ \\ Balu Ananda Chopade' \\ 'Department of Microbiology, \\ University of Pune, Pune, Maharashtra, \\ India; ${ }^{2}$ Institute of Bioinformatics and \\ Biotechnology, University of Pune, \\ Pune, Maharashtra, India; ${ }^{3}$ Department \\ of Chemistry, University of Pune, \\ Pune, Maharashtra, India; ${ }^{4}$ Department \\ of Chemical Engineering, Indian \\ Institute of Technology Bombay, Powai, \\ Mumbai, Maharashtra, India
}

Correspondence: Balu Ananda Chopade Department of Microbiology, University of Pune, Pune 4I I007,

Maharashtra, India

Tel +9l 2025690643

Fax +91 2025690087

Email chopade@unipune.ac.in; bachopade@gmail.com
Background: The development of nontoxic methods of synthesizing nanoparticles is a major step in nanotechnology to allow their application in nanomedicine. The present study aims to biosynthesize silver nanoparticles (AgNPs) using a cell-free extract of Acinetobacter spp. and evaluate their antibacterial activity.

Methods: Eighteen strains of Acinetobacter were screened for AgNP synthesis. AgNPs were characterized using various techniques. Reaction parameters were optimized, and their effect on the morphology of AgNPs was studied. The synergistic potential of AgNPs on 14 antibiotics against seven pathogens was determined by disc-diffusion, broth-microdilution, and minimum bactericidal concentration assays. The efficacy of AgNPs was evaluated as per the minimum inhibitory concentration (MIC) breakpoints of the Clinical and Laboratory Standards Institute (CLSI) guidelines.

Results: Only A. calcoaceticus LRVP54 produced AgNPs within 24 hours. Monodisperse spherical nanoparticles of $8-12 \mathrm{~nm}$ were obtained with $0.7 \mathrm{mM}$ silver nitrate at $70^{\circ} \mathrm{C}$. During optimization, a blue-shift in ultraviolet-visible spectra was seen. X-ray diffraction data and lattice fringes $(d=0.23 \mathrm{~nm}$ ) observed under high-resolution transmission electron microscope confirmed the crystallinity of AgNPs. These AgNPs were found to be more effective against Gram-negative compared with Gram-positive microorganisms. Overall, AgNPs showed the highest synergy with vancomycin in the disc-diffusion assay. For Enterobacter aerogenes, a 3.8-fold increase in inhibition zone area was observed after the addition of AgNPs with vancomycin. Reduction in MIC and minimum bactericidal concentration was observed on exposure of AgNPs with antibiotics. Interestingly, multidrug-resistant $A$. baumannii was highly sensitized in the presence of AgNPs and became susceptible to antibiotics except cephalosporins. Similarly, the vancomycin-resistant strain of Streptococcus mutans was also found to be susceptible to antibiotic treatment when AgNPs were added. These biogenic AgNPs showed significant synergistic activity on the $\beta$-lactam class of antibiotics.

Conclusion: This is the first report of synthesis of AgNPs using A. calcoaceticus LRVP54 and their significant synergistic activity with antibiotics resulting in increased susceptibility of multidrug-resistant bacteria evaluated as per MIC breakpoints of the CLSI standard.

Keywords: Ag nanoparticles, lattice fringes, disc-diffusion, minimum inhibitory concentration, synergistic activity

\section{Introduction}

Nanotechnology is being explored with the goal of improving nanomedicine for human health. ${ }^{1,2}$ There is an interest in the synthesis of nanomaterials because they exhibit 
unique physical, chemical, optical, electrical, magnetic, mechanical, thermal, dielectric, and biological properties, different from those of bulk materials, due to their distinct size- and shape-dependent characteristics. ${ }^{3}$ Silver is a natural antimicrobial agent. ${ }^{4}$ Therefore, silver nanoparticles (AgNPs) exhibit great potential as novel antimicrobial agents. Besides their antimicrobial properties, AgNPs are also reported to exhibit anti-angiogenesis, ${ }^{5}$ anti-inflammatory, ${ }^{6}$ and antiplatelet ${ }^{7}$ activities. Hence, AgNPs have diverse medical applications. ${ }^{8-10}$ Although there are reports on the antimicrobial activity of free AgNPs and in combination with antibiotics, ${ }^{11-16}$ very few reports have examined the effect of AgNPs on antibiotics belonging to different classes. ${ }^{17}$

AgNPs can be synthesized by chemical, ${ }^{18}$ physical, ${ }^{19,20}$ or biological routes involving plants ${ }^{8,17,21,22}$ or microorganisms..$^{23-28}$ Biological synthesis is preferred nowadays because these methods are safe, cheap, eco-friendly, and do not involve any toxic substrate or by-product. ${ }^{29}$ Unlike plants, microbial-mediated synthesis of nanoparticles is not affected by geographical and seasonal variations, avoiding inconsistent morphologies and properties. Reports are available on AgNP synthesis employing pathogenic and nonpathogenic bacterial cells and/ or supernatant such as Klebsiella pneumoniae, Enterobacter spp., Pseudomonas aeruginosa, and Bacillus spp.. ${ }^{14,25-28}$ Microorganisms synthesize nanoparticles either intra- or extracellularly. Extracellular synthesis has advantages, since retrieval of nanoparticles is easy compared with intracellular synthesis where additional recovery steps are required.

Acinetobacter spp. is most commonly found in the environment including human skin microbiota ${ }^{30}$ and the mucus membrane of the upper respiratory tract. ${ }^{31}$ It is a versatile group of microbes with respect to nutrition, metabolism, and genetic organization. ${ }^{32}$ Acinetobacter spp. have been reported to exhibit metal resistance ${ }^{33}$ and plant growth-promoting properties such as phosphate and zinc solubilization, ${ }^{34}$ implying their ability to interact with metals rendering them nontoxic for their survival. So far there are only two preliminary reports which have included Acinetobacter spp. for synthesis of AgNPs; one being A. schindleri isolated from soil, ${ }^{35}$ and another is $A$. calcoaceticus $\mathrm{W} 17 .{ }^{36}$ However, detailed reports on the synthesis of AgNPs by genus Acinetobacter are not known. In view of this background, we proposed that Acinetobacter isolated from wheat rhizosphere may produce novel and unique nanoparticles with respect to size, shape, and biological activities. We also investigated the effects of reaction parameters on the rate of synthesis and morphology of the AgNPs. Synergistic effects of these AgNPs on activity of different antibiotics have been evaluated against pathogenic Gram-negative and Gram-positive bacteria.

\section{Material and methods Cultures}

Eighteen strains of Acinetobacter spp., isolated from the wheat rhizosphere (Pune, Maharashtra, India), were used to screen the synthesis of AgNPs. ${ }^{34}$ These were already identified by $16 \mathrm{~S}$ rRNA sequencing (GenBank EU221346, EU221386, EU221389, EU921458-EU921472). The cultures were maintained on a Luria Bertani (HiMedia, Mumbai, India) agar plate/slant at $4^{\circ} \mathrm{C}$ and as glycerol stocks at $-80^{\circ} \mathrm{C}$. For inoculum preparation, a loopful of the culture was inoculated into $250 \mathrm{~mL}$ sterile Luria Bertani broth and incubated at $30^{\circ} \mathrm{C} / 200 \mathrm{rpm}$ for 24 hours. The cells were harvested by centrifugation at $6,000 \mathrm{rpm}$ for 7 minutes at $4{ }^{\circ} \mathrm{C}$.

Standard cultures for antibacterial assays were procured from Microbial Type Culture Collection (MTCC), Chandigarh, India and National Collection of Industrial Microorganisms (NCIM), Pune, India. These include Gram-negative (Enterobacter aerogenes NCIM 2964, Escherichia coli ATCC 25922, Pseudomonas aeruginosa NCIM 5029, Shigella sonnie MTCC 2957, Salmonella typhimurium NCIM 2509), and Gram-positive (Staphylococcus aureus MTCC 3160, Streptococcus mutans MTCC 497) bacterial pathogens. Acinetobacter baumannii AIIMS 7 (GenBank EU779829) isolated and identified in our laboratory has been used. ${ }^{37}$

\section{Synthesis of AgNPs and ultraviolet-visible (UV-Vis) spectra analysis}

For screening, the cells of Acinetobacter spp. (optical density $[\mathrm{OD}]_{600} \approx 1 \times 10^{10} \mathrm{CFU} / \mathrm{mL}$ ) were suspended into sterile Milli- $Q^{\circledR}$ water $(\mathrm{pH} 7)$ after repeated rinses to remove the traces of media and incubated at $30^{\circ} \mathrm{C} / 200 \mathrm{rpm}$ for 72 hours. Cell-free extract (CFE) used for synthesis was collected by passing the supernatant obtained after centrifugation through a $0.2 \mu \mathrm{m}$ syringe filter (Pall Corporation, Port Washington, NY, USA). Three flasks, the first containing $1 \mathrm{mM} \mathrm{AgNO}_{3}$ (HiMedia) without CFE, the second containing only CFE, and the third containing CFE with $1 \mathrm{mMAgNO}_{3}$, were incubated at $40^{\circ} \mathrm{C}$ in static conditions. Synthesis of AgNPs was visually observed for a color change over a period of 168 hours. Reduction of $\mathrm{Ag}^{+}$ions was monitored by recording the UVVis spectrum between 300 and $800 \mathrm{~nm}$ at regular intervals up to 168 hours on SpectraMax M5 Multi-mode Microplate Reader (Molecular Devices LLC, Sunnyvale, CA, USA). The strain giving maximum absorbance was selected.

\section{Characterization of AgNPs}

After 168 hours of synthesis, the sample of AgNPs was centrifuged at 14,000 rpm for 30 minutes at room temperature. 
Repeated rinses were performed to remove impurities. The pellet of AgNPs was suspended in $1 \mathrm{~mL}$ sterile Milli-Q water. The X-ray diffraction (XRD) data of dried thin films of AgNPs on a glass slide was recorded by D8 Advanced Brucker X-ray diffractometer with a $\mathrm{Cu} \mathrm{K} \alpha(1.5 \AA)$ source. A drop of AgNP sample was dried on a glass slide for analysis under a scanning electron microscope (SEM) (JSM-6360; JEOL, Tokyo, Japan) at $20 \mathrm{kV}$ accelerating voltage. Samples for transmission electron microscopy (TEM) and high-resolution TEM (HR-TEM) were prepared by drop-coating the AgNPs solution on a carbon-coated copper grid and drying under infrared radiation. The analyses were performed on FEI Tecnai $\mathrm{G}^{2} 12$ BioTwin (FEI Company, Eindhoven, the Netherlands) TEM and JEM-2100 (JEOL) HR-TEM. The presence of elemental silver was confirmed through energy-dispersive spectroscopy (EDS) (JED-2300; JEOL), equipment included with the HRTEM. The particle size of a $3 \mathrm{~mL}$ sample was estimated using a dynamic light scattering instrument (Zetasizer Nano-2590; Malvern Instruments Ltd, Worcestershire, UK) in a polystyrene cuvette.

\section{Effect of reaction parameters on morphology of AgNPs}

To obtain the optimized reaction parameters giving maximum synthesis of AgNPs, firstly, $\mathrm{AgNO}_{3}$ ranging from 0.5 to $5 \mathrm{mM}$ (final concentration) was added to the CFE and incubated at $40^{\circ} \mathrm{C}$ for up to 168 hours. After this, the optimum concentration of $\mathrm{AgNO}_{3}$ was added to the CFE and incubated for 168 hours at $4^{\circ} \mathrm{C}-80^{\circ} \mathrm{C}$ for temperature optimization. Besides UV-Vis spectra, TEM analyses were carried out to study morphology with varying salt concentrations and reaction temperatures.

\section{Antibacterial assay}

Fourteen antibiotics, namely, amikacin, gentamicin, kanamycin, amoxicillin, ampicillin, ceftriaxone, vancomycin, ciprofloxacin, doxycycline, tetracycline, chloramphenicol (HiMedia, Mumbai, India), trimethoprim (Sigma-Aldrich, St. Louis, MO, USA), ceftazidime (GlaxoSmithKline Pharmaceutical Limited, Nashik, India), and penicillin (Alembic Pharmaceutical Limited, Vadodara, India), were used for antibacterial assay. The disc-diffusion method was used to assay the antibacterial activity of the AgNPs, antibiotics, and combination of both against pathogenic bacteria on MuellerHinton (MH) (HiMedia) agar plates. In brief, a single colony of each test strain was grown overnight in $\mathrm{MH}$ broth on a rotary shaker $(150 \mathrm{rpm})$ at $37^{\circ} \mathrm{C}$. The $\mathrm{OD}$ was adjusted to 0.5 McFarland $\left(\approx 1 \times 10^{8} \mathrm{CFU} / \mathrm{mL}\right)$, and cultures were applied to the plates along with discs containing AgNPs $(1-1,024 \mu \mathrm{g} /$ disc) and antibiotics (30 $\mathrm{g} / \mathrm{disc})$. To determine the synergistic effects, discs with $30 \mu \mathrm{g}$ of antibiotic were further impregnated with $5 \mu \mathrm{L}$ of freshly prepared AgNPs (15 $\mu \mathrm{g} /$ disc). After incubation at $37^{\circ} \mathrm{C}$ for 20 hours, the zones of inhibition were measured. The assays were performed in duplicate.

The minimum inhibitory concentration (MIC) was determined by broth microdilution method given by the Clinical Laboratory Standards Institute (CLSI) using 96-well microtiter plates. Two-fold serial dilutions of AgNPs and antibiotics were made using $\mathrm{MH}$ broth. Each plate included growth and sterility control wells. To each well, $5 \mu \mathrm{L}$ inoculum $\left(\approx 5 \times 10^{5} \mathrm{CFU} / \mathrm{mL}\right)$ was added. To evaluate the effect of AgNPs on MICs of antibiotics, a subinhibitory concentration of AgNPs was added to the wells containing different concentrations of antibiotics so that the final concentration of AgNPs in each well was $15 \mu \mathrm{g}$. The microtiter plates were incubated at $37^{\circ} \mathrm{C}$ for 20 hours, and results were recorded. The lowest concentration completely inhibiting the growth as detected by the unaided eye was reported as the MIC. The assays were performed in duplicate. MIC breakpoints of the CLSI $2007^{38}$ guidelines were used to define a resistant or susceptible strain.

From the above assay, a $5 \mu \mathrm{L}$ aliquot was taken from the wells showing no visual growth after incubation and spotted onto $\mathrm{MH}$ agar plates. The lowest concentration showing no colony on the $\mathrm{MH}$ agar after 20 hours of incubation at $37^{\circ} \mathrm{C}$ was recorded as the minimum bactericidal concentration. These were performed in duplicate.

\section{Results and discussion Synthesis of AgNPs}

A study on the biosynthesis of AgNPs by CFE of 18 strains of Acinetobacter spp. isolated from the wheat rhizosphere was carried out. Only A. calcoaceticus LRVP54 gave a positive result for synthesis of AgNPs within 24 hours. This indicates that although these bacteria possess plant growth-promoting properties, ${ }^{34}$ only one has the ability to synthesize AgNPs. Visual observation of CFE incubated with $\mathrm{AgNO}_{3}$ showed a color change from colorless to reddish brown, clearly indicating the formation of AgNPs (Figure 1A). In the UV-Vis spectrum, a single, strong, and broad peak was observed at $440 \mathrm{~nm}$, confirming the synthesis of AgNPs using CFE (Figure 1A). In metal nanoparticles such as silver, the electrons move freely due to the close proximity of the conduction and valence bands. ${ }^{39}$ The collective oscillation of electrons of AgNPs in resonance with the light wave gives rise to a unique surface plasmon resonance (SPR) absorption band which is also the origin of the observed color. ${ }^{40,41}$ A peak located between 410 and $440 \mathrm{~nm}$ has been observed for AgNPs and is well documented for metal nanoparticles with sizes from 2 to 

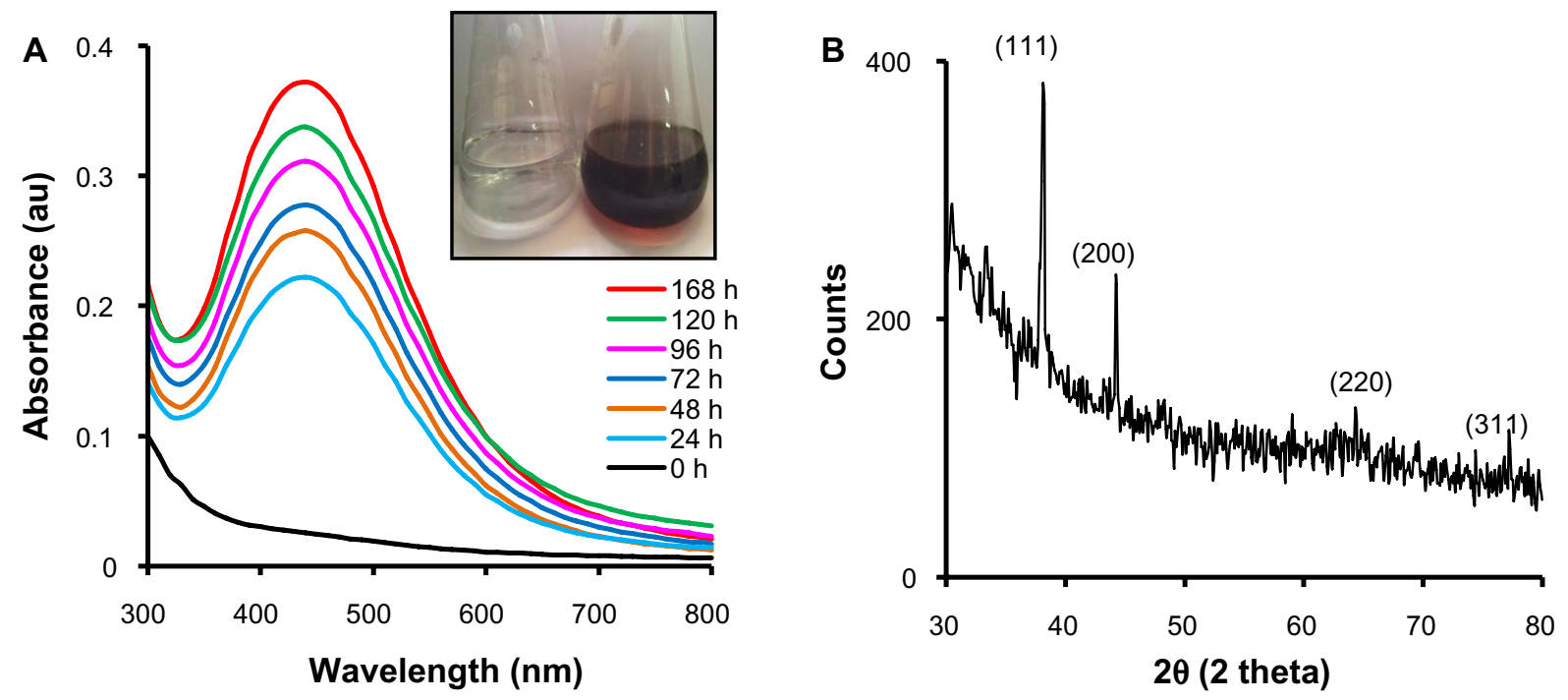

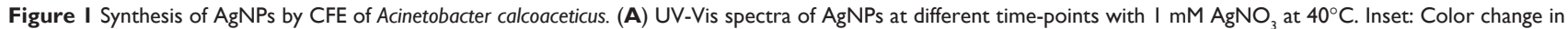

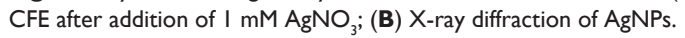

Abbreviations: AgNP, silver nanoparticle; CFE, cell-free extract; UV-Vis, ultraviolet and visible absorption; $\mathrm{AgNO}_{3}$, silver nitrate; au, arbitrary units; h, hours.

$100 \mathrm{~nm} .{ }^{41}$ According to Mie's theory, only a single SPR band is expected in the absorption spectra of spherical metal nanoparticles, whereas anisotropic particles could give rise to two or more SPR bands, depending on the shape of the particles. ${ }^{42,43}$ In our case, a single SPR peak was observed, which suggests that our AgNPs were spherical in shape and is consistent with the TEM observations. With the progress of reaction time, more and more $\mathrm{Ag}^{+}$were reduced to $\mathrm{Ag}^{0}$, resulting in an increased concentration of AgNPs as indicated by increased OD of the SPR band $\left(\lambda_{\max }=440 \mathrm{~nm}\right)$ with time. The major reason for SPR broadening is electron surface scattering, which may be enhanced for small aggregates. ${ }^{40} \mathrm{AgNPs}$ formed in this process were stable, and the absorption spectra found to be unaltered even after 6 months at room temperature.

The mechanism behind biosynthesis of AgNPs using microorganisms is still not clear. Peptides, proteins, and DNA have been suggested to act as templates for reducing metal ions to form nanoparticles. ${ }^{23,44}-47$ There are reports suggesting the involvement of enzymes such as nitrate reductase and phyochelatin synthase as reducing agents for AgNPs synthesis in bacteria and fungi. ${ }^{23,46,47} \mathrm{We}$ observed that the nanoparticles were embedded in an organic matrix. It seems that these biomolecules are secreted by the cells in the CFE, which may act as reducing and stabilizing agents.

\section{Characterization of AgNPs}

The exact nature of the AgNPs can be deduced from the XRD spectrum of the sample. The XRD pattern (Figure 1B) showed four peaks at $2 \theta$ values of $38.1^{\circ}, 44.3^{\circ}, 64.4^{\circ}$, and $77.2^{\circ}$, corresponding to (111), (200), (220), and (311) respectively, in the whole spectrum of $2 \theta$ values ranging from $20^{\circ}$ to $80^{\circ}$. A comparison of our XRD spectrum with the Standard (JCPDS file no 04-0783) confirmed the formation of crystalline AgNPs, in accordance with the study of Kalimuthu et al. ${ }^{27}$ SEM of the sample showed the formation of nanoparticles in dispersed and aggregated forms which were confirmed to be of silver by EDS (Figure 2A and B). EDS analysis showed a peak at $3 \mathrm{keV}$, which is typical for the absorption of metallic silver nanocrystallites due to SPR, thereby confirming the formation of AgNPs. ${ }^{14}$ Additional peaks for copper were observed due to the copper grid used for EDS analysis. TEM analyses revealed the synthesis of polydisperse AgNPs of $10-60 \mathrm{~nm}$ size from $1 \mathrm{mM} \mathrm{AgNO}_{3}$ after 168 hours. Aggregates and dispersed nanoparticles were found to be embedded in an organic matrix (Figure 2C). Namasivayam et al employed a similar method for biosynthesis of AgNPs using CFE of Lactobacillus acidophilus 01 where production of spherical AgNPs of $45-60 \mathrm{~nm}$ was reported. ${ }^{24}$ Dynamic light scattering data (Figure 2C) showed that the majority of AgNPs synthesized with $1 \mathrm{mM} \mathrm{AgNO}_{3}$ were in the range of $15-60 \mathrm{~nm}$, along with some aggregates, which is well in agreement with SEM and TEM results. Also HR-TEM imaging distinctly showed the lattice fringes wherein $d$ (the distance between two lattice fringes) was $0.23 \mathrm{~nm}$ (Figure 2D), typically observed for the crystalline structure of the AgNPs. ${ }^{22}$

\section{Effect of reaction parameters on morphology of AgNPs}

Optimization studies revealed the significant effects of concentration of metal salt and reaction temperature on the rate of bioreduction of silver ions to AgNPs. Morphological 


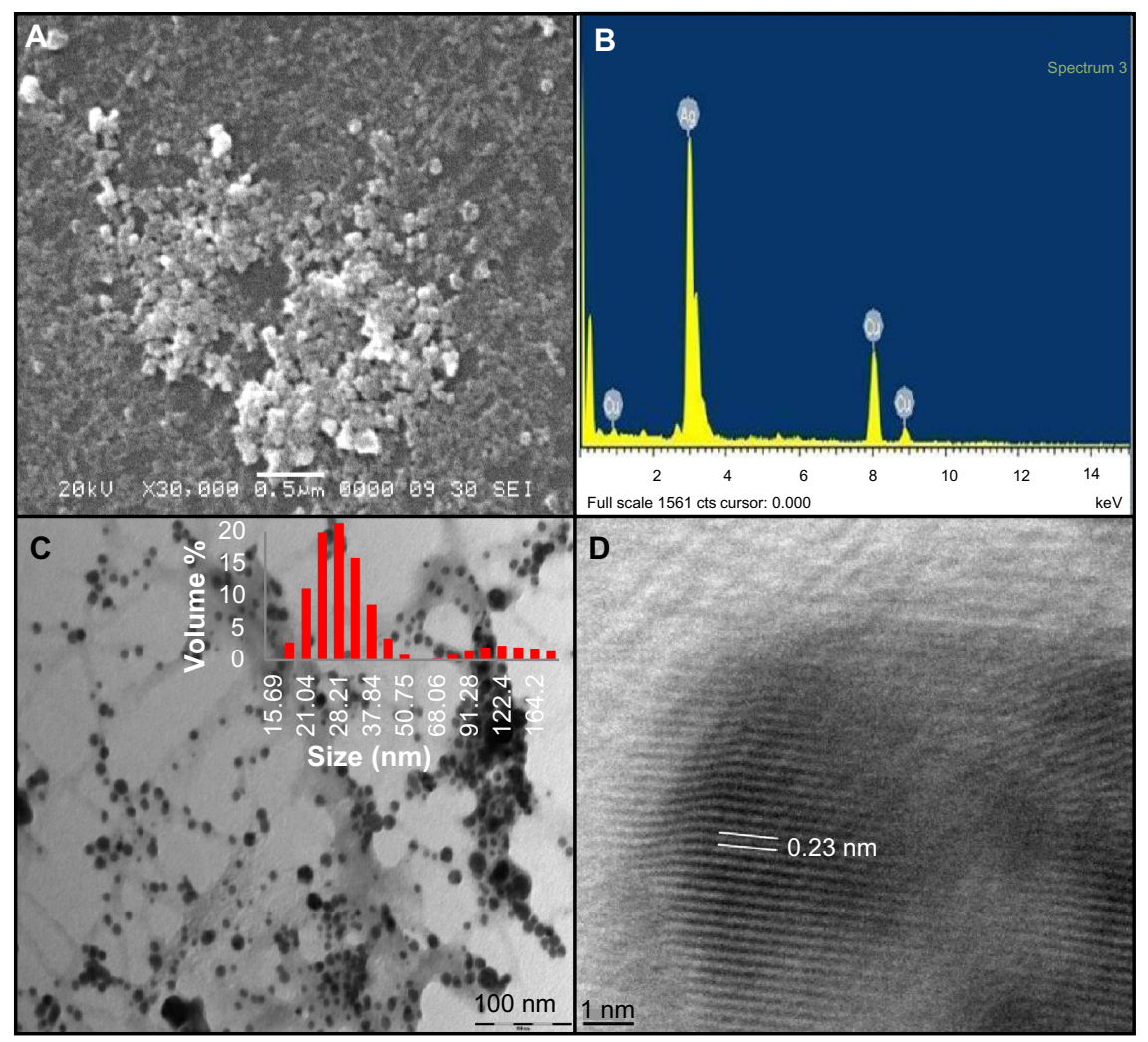

Figure 2 Characterization of $\mathrm{AgNPs}$ synthesized with $1 \mathrm{mM} \mathrm{AgNO}$ at $40^{\circ} \mathrm{C}$. (A) scanning electron microscopy image; (B) energy dispersive spectroscopy spectrum; (C) TEM image. Inset: Particle size distribution by dynamic light scattering; (D) HR-TEM image of AgNPs $(d=0.23 \mathrm{~nm})$.

Abbreviations: $\mathrm{AgNP}$, silver nanoparticle; $\mathrm{AgNO}_{3}$, silver nitrate; TEM, transmission electron microscopy; HR-TEM, high-resolution transmission electron microscopy.

changes during variation of parameters were observed under TEM. At a fixed temperature of $40^{\circ} \mathrm{C}$, variation in reaction kinetics was observed for the synthesis of nanoparticles by varying the $\mathrm{AgNO}_{3}$ concentration (Figure 3A). Maximum synthesis of nanoparticles occurred at $0.7 \mathrm{mM} \mathrm{AgNO}_{3}$ in the reaction mixture, followed by $0.5 \mathrm{mM} \mathrm{AgNO}_{3}$. Highest concentration of $5 \mathrm{mM} \mathrm{AgNO}_{3}$ showed the least bioreduction of silver ions to nanoparticles. This can be explained on the basis of enzyme-substrate kinetics; ie, the active site in the key biomolecule responsible for reduction is already saturated with the silver ions, and no site is available for excess ions to get reduced, hence there is no further increase in synthesis
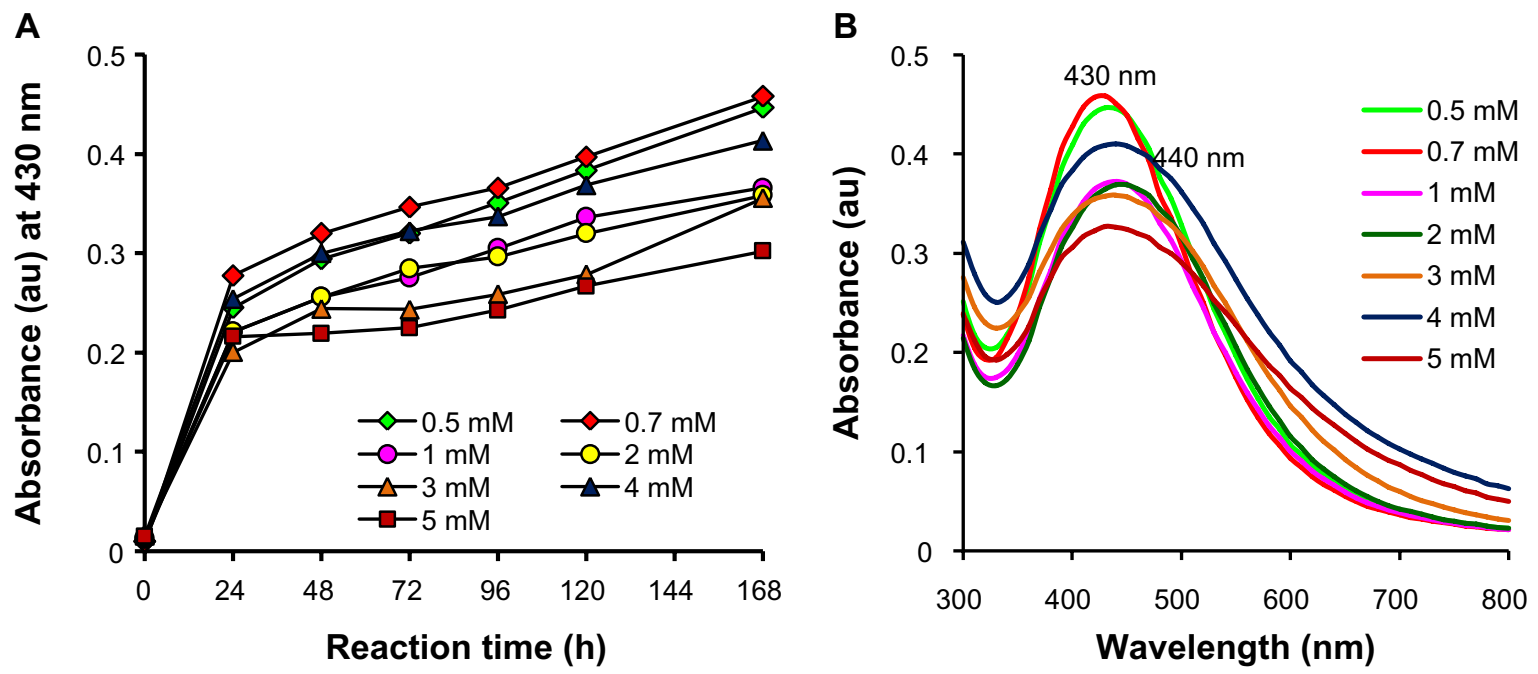

Figure 3 Optimization of $\mathrm{AgNO}_{3}$ concentration for AgNP synthesis. (A) Time course of $\mathrm{AgNP}$ synthesis at $40^{\circ} \mathrm{C}$ using different concentrations of $\mathrm{AgNO}{ }_{3}$; (B) UV-Vis spectra of $\mathrm{AgNP}$ synthesis at $40^{\circ} \mathrm{C}$ after 168 hours obtained with different concentrations of $\mathrm{AgNO}_{3}$.

Abbreviations: $\mathrm{AgNO}_{3}$, silver nitrate; AgNP, silver nanoparticle; UV-Vis, ultraviolet and visible absorption spectroscopy; au, arbitrary units; h, hours. 
of AgNPs despite the addition of more salt. As compared with the UV-Vis spectrum obtained for $1 \mathrm{mM} \mathrm{AgNO}_{3}$ after 168 hours, a blue shift from 440 to $430 \mathrm{~nm}$ was observed at $0.7 \mathrm{mM}$ (Figure 3B), which could be due to the variation in morphology of nanoparticles synthesized with different salt concentrations. At the optimized $\mathrm{AgNO}_{3}$ concentration of $0.7 \mathrm{mM}$, rate of synthesis was found to increase with an increase in reaction temperature up to $70^{\circ} \mathrm{C}$, which showed maximum synthesis (Figure 4A), after which a decline in the synthesis was observed. A further blue shift in the SPR peak to $420 \mathrm{~nm}$ was observed at $70^{\circ} \mathrm{C}$ after 168 hours of incubation (Figure 4B). It has been reported that small and homogeneous distribution of AgNPs causes the blue shift in UV-Vis spectrum, ${ }^{48}$ parallel with our results as confirmed by UV-Vis spectrum and TEM images.

TEM analysis showed the formation of monodisperse spherical AgNPs of 8-12 nm size at $70^{\circ} \mathrm{C}$ with $0.7 \mathrm{mM}$ $\mathrm{AgNO}_{3}$ (Figure 5). Deviations from these optimized parameters resulted in an increase in size and polydispersity of AgNPs as observed under TEM. Despite a large number of reports on the synthesis of AgNPs using bacteria, only few reports are available on the optimization. One such study was reported by Gurunathan et al, for E. coli-mediated AgNP synthesis, where $5 \mathrm{mM} \mathrm{AgNO}_{3}, 60^{\circ} \mathrm{C}$ temperature, and $\mathrm{pH} 10$ were reported to provide optimal conditions for the maximal synthesis of small sized nanoparticles. ${ }^{49}$ In the present study, the enhanced rate of synthesis of AgNPs at optimized conditions might be the direct result of the effect of substrate (silver ions) and temperature on a key biomol- ecule responsible for reduction present in the CFE of $A$. calcoaceticus LRVP54. It has been suggested that increase in reaction rate causes most silver ions to be consumed in the formation of nuclei and thus stops the secondary reduction process on the surface of the preformed nuclei, leading to the formation of smaller size particles. ${ }^{49}$ However, to have completely monodisperse nanoparticles through biological systems is still a big challenge.

\section{Antibacterial activity of AgNPs}

Silver and its compounds are known for their antimicrobial properties and for the treatment of burns and chronic wounds. ${ }^{50,51}$ High surface area to volume ratio cause high bactericidal activity of AgNPs compared with bulk silver metal. ${ }^{52,53}$ Here, individual and combined effects of AgNPs with 14 antibiotics belonging to seven classes were investigated against seven pathogenic bacteria using the discdiffusion method. AgNPs exhibited antibacterial activity against $P$. aeruginosa and $A$. baumannii compared with $S$. aureus and $S$. mutans as observed by the zone of inhibition (Table S1). Similar results were obtained by Fayaz et al. ${ }^{16}$ The reason for this is the structural difference in cell wall composition of Gram-positive and Gram-negative bacteria. Gram-positive bacteria possess a thick layer of peptidoglycan (20-80 nm), making it difficult for AgNPs to penetrate. ${ }^{16}$ Wide variation has been found in the activities of antibiotics in the presence and absence of AgNPs, which is interpreted in terms of an increase in the area of zones of inhibition (Table 1). Aminoglycosides showed a minute increase in the
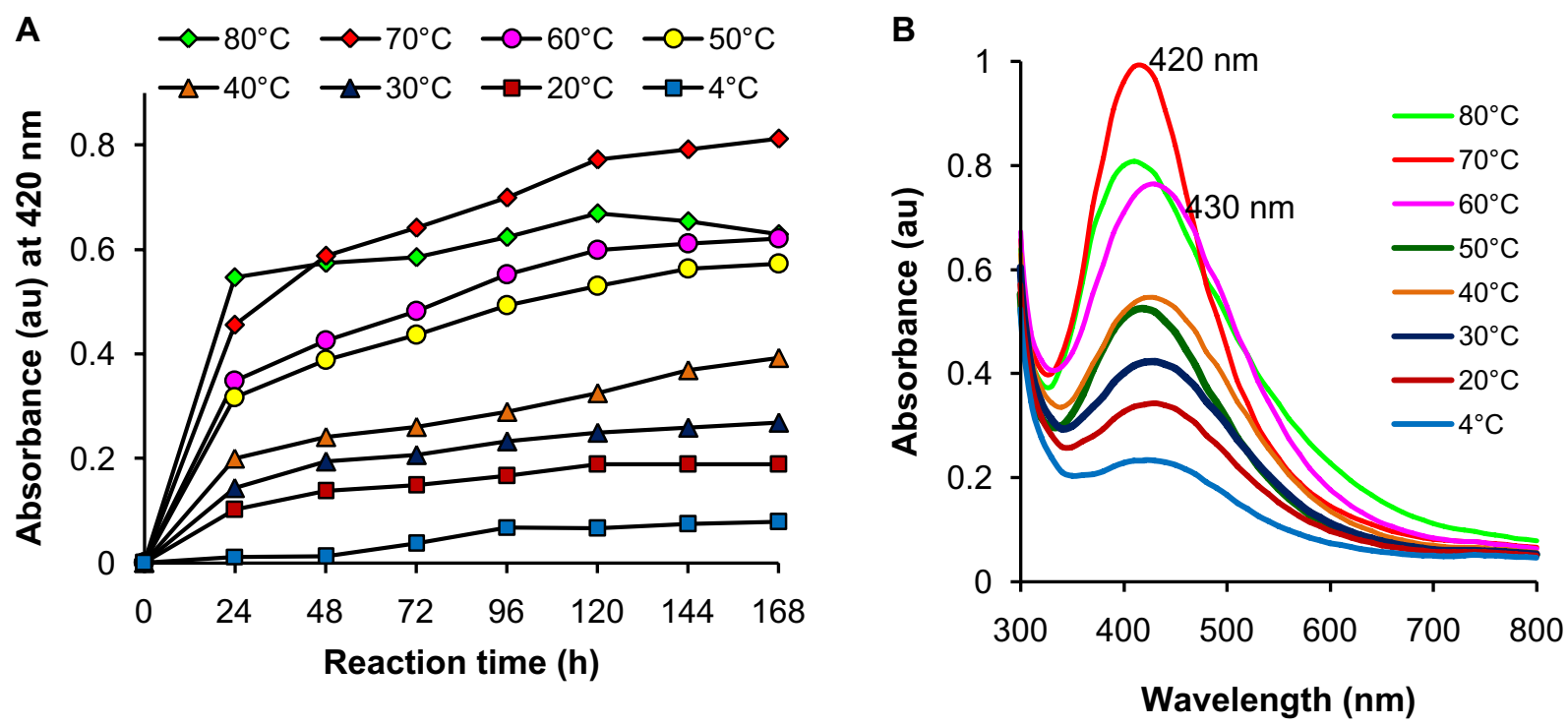

Figure 4 Optimization of reaction temperature for AgNP synthesis. (A) Time course of AgNP synthesis with $0.7 \mathrm{mM} \mathrm{AgNO}_{3}$ at different reaction temperatures; (B) UV-Vis spectrum for AgNP synthesis with $0.7 \mathrm{mM} \mathrm{AgNO}_{3}$ after 168 hours at different reaction temperatures.

Abbreviations: $\mathrm{AgNP}$, silver nanoparticle; $\mathrm{AgNO}_{3}$, silver nitrate; UV-Vis, ultraviolet and visible absorption spectroscopy; au, arbitrary units; h, hours. 

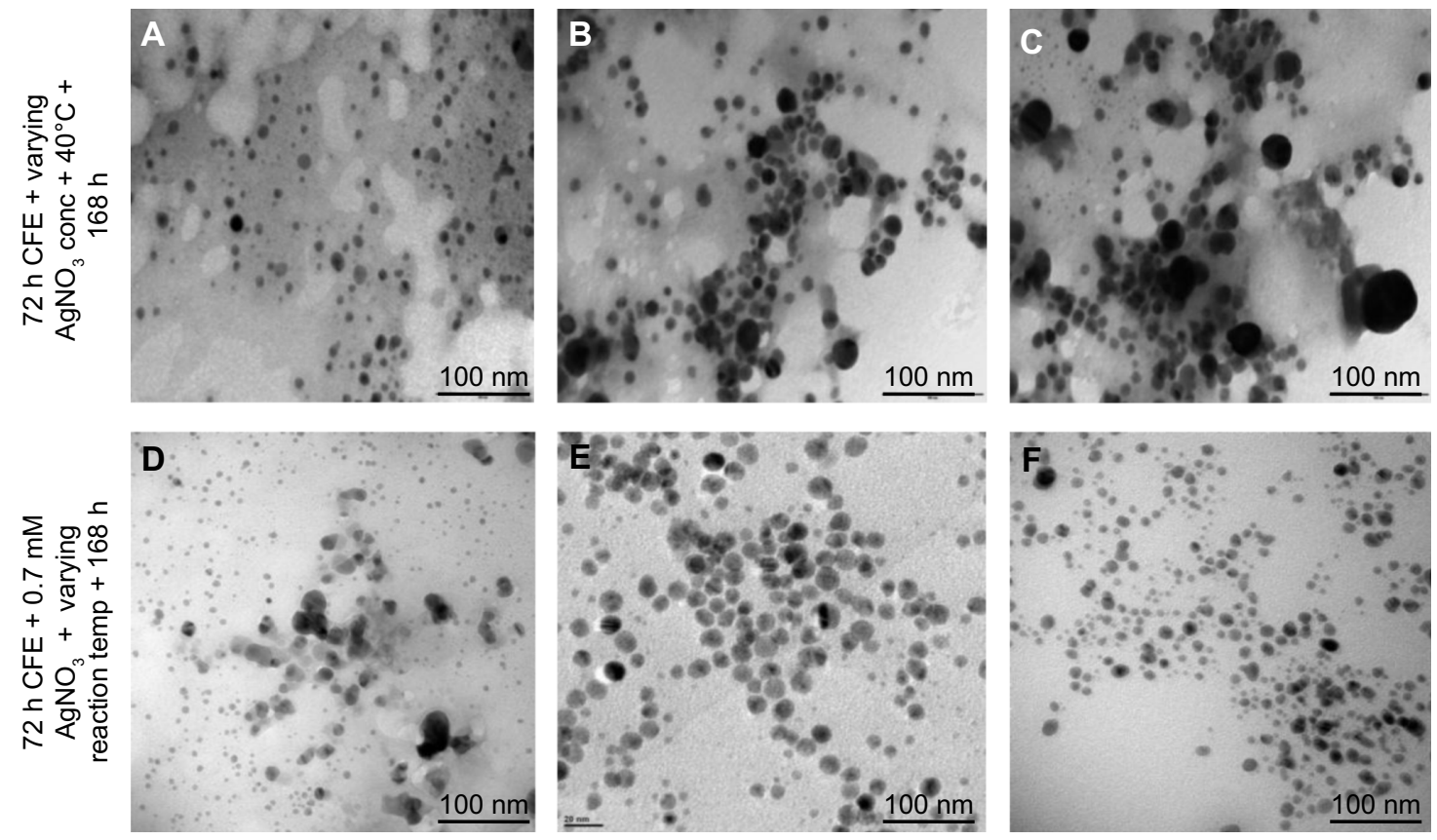

Figure 5 Morphology of AgNPs synthesized at varying reaction parameters. Upper panel shows the TEM images for AgNPs synthesized at $40^{\circ} \mathrm{C}$ with (A) $0.7 \mathrm{mM}$, (B) $2 \mathrm{mM}$, and (C) $4 \mathrm{mM}$ silver salt after 168 hours. Lower panel shows the TEM images for $\mathrm{AgNP}$ biosynthesis with $0.7 \mathrm{mM} \mathrm{AgNO}$ at (D) $60^{\circ} \mathrm{C},(\mathbf{E}) 70^{\circ} \mathrm{C}$, and (F) $80^{\circ} \mathrm{C}$ after 168 hours.

Abbreviations: AgNP, silver nanoparticle; $\mathrm{AgNO}_{3}$, silver nitrate; TEM, transmission electron microscopy; CFE, cell-free extract, conc, concentration; temp, temperature; h, hours.

range $0.0-0.8$ fold, with the exception of gentamicin against $A$. baumannii and kanamycin against $P$. aeruginosa, where a 1.8-fold increase was seen. Considerable enhancement in antibacterial activity was observed for amoxicillin in the presence of AgNPs against $P$. aeruginosa, where a 1.8-fold increase was observed. For penicillin, in the presence of AgNPs, a 3.0-fold increase against S. mutans was observed. Vancomycin was found to have the highest overall synergistic activity in combination with AgNPs compared with all other antibiotics. For E. aerogenes, a 3.8-fold increase in inhibition zone was observed with the combination of vancomycin and AgNPs. In a similar study, Ghosh et al reported the synergy using a $30 \mu \mathrm{g} /$ disc of AgNPs synthesized by Dioscorea bulbifera tuber extract and $500 \mu \mathrm{g}$ of each antibiotic. ${ }^{17}$ Our findings are comparable to their results even though we only used $30 \mu \mathrm{g} / \mathrm{disc}$ of antibiotics and $15 \mu \mathrm{g} / \mathrm{disc}$ of AgNPs.

The broth dilution assay was performed to determine the MIC. For AgNPs, MIC was in the range of $150-600 \mathrm{mg} / \mathrm{L}$ against Gram-negative bacteria, while for $S$. aureus and S. mutans, it was $>1,000 \mathrm{mg} / \mathrm{L}$. Therefore, to evaluate the synergistic effects of AgNPs on the respective MICs of antibiotics, a sub-inhibitory concentration of $75 \mathrm{mg} / \mathrm{L} \mathrm{AgNPs}$ was added to each well (15 $\mu \mathrm{g} /$ well). MIC breakpoints of the CLSI guidelines ${ }^{38}$ were used for comparison of the obtained results (Table 2). MIC breakpoints are provided to define the resistance and susceptibility of pathogenic microorganisms depending on the extent of their antibiotic resistance. Interpretation of the antimicrobial results as per these guidelines will provide a greater understanding of the efficacy of AgNPs and their synergistic effects on antibiotics against pathogenic microorganisms. E. coli ATCC 25922, a control strain, was included in the study to check the accuracy of determined MICs. Out of seven bacteria, six exhibited resistance to one or more antibiotics belonging to the $\beta$-lactam class (Table 2). With the addition of AgNPs, only Gram-negative bacteria were found to have a MIC in the susceptible range. Although a decrease in MIC was observed, $S$. aureus and $S$. mutans still exhibited resistance towards $\beta$-lactam antibiotics. Significant synergistic effects of AgNPs were observed against $A$. baumannii, which showed resistance to seven of the ten antibiotics. On exposure to AgNPs in combination with the antibiotics, the MICs were reduced significantly, and the bacteria were found to be susceptible to all of the antibiotics tested except cephalosporins, where no change was observed. Although Gram-positive bacteria showed resistance towards vancomycin, addition of AgNPs not only reduced the MIC but also made $S$. mutans susceptible to the antibiotic treatment. All pathogens were already susceptible to the tetracycline class of antibiotics; therefore, treatment with AgNPs was unnecessary, although a decrease in MICs could be observed. The corresponding minimum bactericidal concentrations of these bacteria were also reduced on 


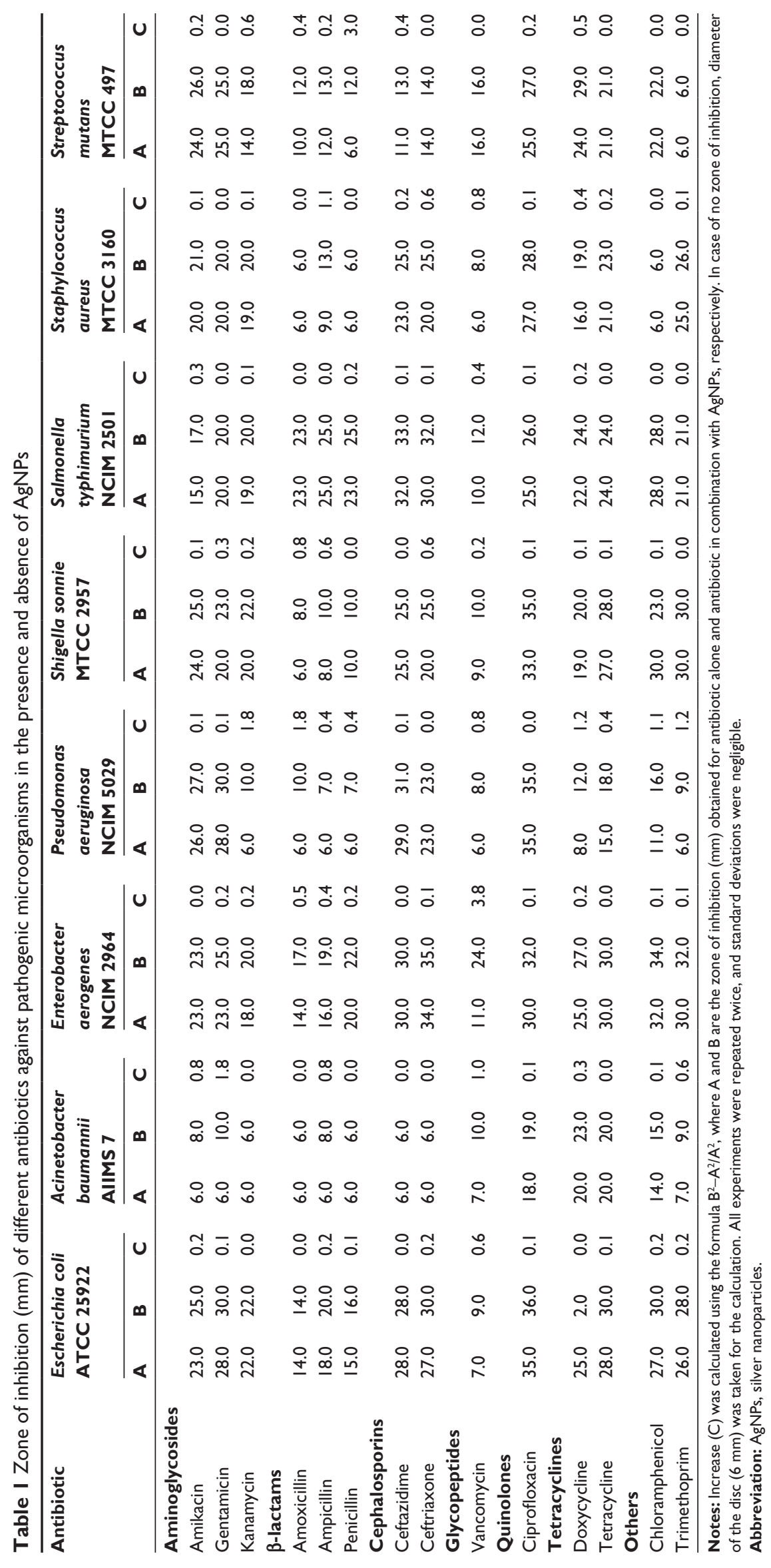




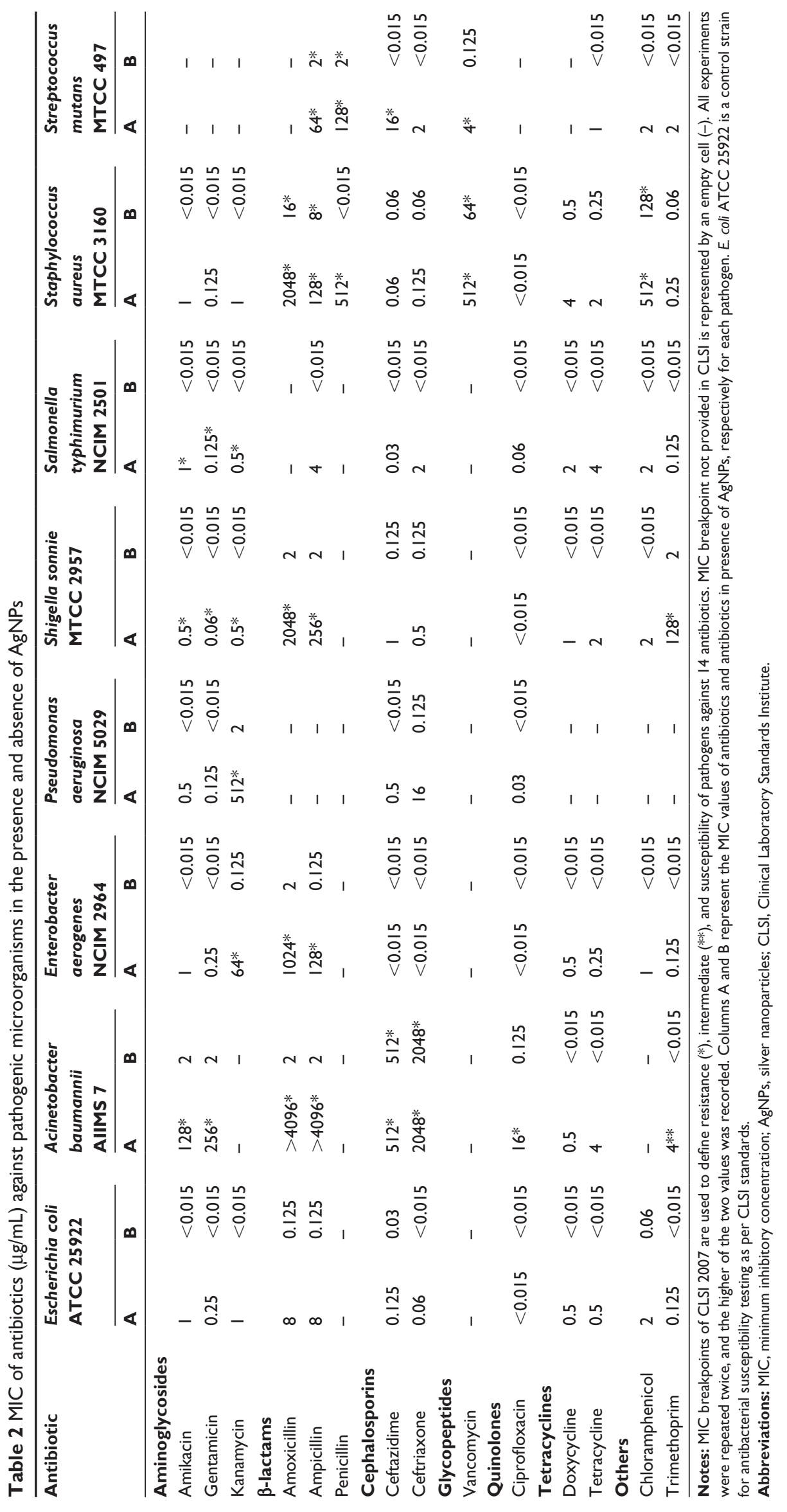


addition of AgNPs in combination with antibiotics (Table S2). It is important to note that although there are large numbers of reports on MICs of AgNPs against bacterial pathogens, ${ }^{54-56}$ no study has been done to evaluate the synergistic potential of AgNPs with respect to the known CLSI standards. However, in this study, we not only showed the synergistic effects of AgNPs on the activity of antibiotics, but also determined its significance using MIC breakpoints given in the CLSI guidelines. This shows that the administration of a small amount of AgNPs in combination with antibiotics can reduce the required dose of antibiotics by up to a 1000 -fold to achieve the same effect besides combating the problem of multidrug resistance among pathogenic bacteria.

Antibacterial mechanisms of antibiotics are wellknown. ${ }^{57}$ Multiple mechanisms have been suggested to explain the antibacterial activity of AgNPs, such as release of silver ions from AgNPs, ${ }^{16}$ generation of reactive oxygen species, disruption of cellular morphology, inactivation of vital enzymes, DNA condensation, ${ }^{11}$ and loss of DNA replication. ${ }^{58}$ Emerging resistance among bacteria renders the available antibiotics inefficient. Synergistic action of AgNPs and antibiotics resulted in enhanced antibacterial effect. Moreover, simultaneous action of antibiotics and AgNPs will make it difficult for pathogenic bacteria to develop resistance, and hence, this combinational therapy can be further studied to develop new formulations of AgNPs in conjunction with antibiotics.

\section{Conclusion}

This is the first report on biological synthesis of AgNPs using A. calcoaceticus LRVP54, an environmental isolate from the wheat rhizosphere. The optimization of reaction parameters resulted in monodisperse spherical AgNPs of size 8-12 nm. The efficiency of AgNPs to increase the susceptibility of drug-resistant bacteria measured as per MIC breakpoints of the CLSI standard we report here for the first time. Further studies on the mechanistic aspect of biosynthesis of AgNPs, and their bactericidal activity are currently under investigation.

\section{Acknowledgments}

Authors RS, SW, and SG are thankful to the University Grant Commission (UGC), New Delhi, India for the Research Fellowship. Part of this work was supported by University of Potential Excellence II (2012-2017) awarded to the University of Pune, Pune, India by UGC. We also acknowledge the support of the Department of Physics, University of Pune for XRD, SEM-EDS, and TEM measurements.

\section{Disclosure}

The authors report no conflicts of interest in this work.

\section{References}

1. Soloviev M. Nanobiotechnology today: focus on nanoparticles. J Nanobiotechnology. 2007;5:11.

2. Chatterjee S, Bandyopadhyay A, Sarkar K. Effect of iron oxide and gold nanoparticles on bacterial growth leading towards biological application. J Nanobiotechnology. 2011;9:34.

3. Schmid G. Large clusters and colloids. Metals in the embryonic state. Chem Rev. 1992;92(8):1709-1727.

4. Deshpande LM, Kapadnis BP, Chopade BA. Metal resistance in Acinetobacter and its relation to beta-lactamase production. Biometals. 1993;6(1):55-59.

5. Kang K, Lim DH, Choi IH, et al. Vascular tube formation and angiogenesis induced by polyvinylpyrrolidone-coated silver nanoparticles. Toxicol Lett. 2011;205(3):227-234.

6. Martínez-Gutierrez F, Thi EP, Silverman JM, et al. Antibacterial activity, inflammatory response, coagulation, and cytotoxicity effects of silver nanoparticles. Nanomedicine. 2012;8(3):328-336.

7. Ragaseema VM, Unnikrishnan S, Kalliyana Krishnan V, et al. The antithrombotic and antimicrobial properties of PEG-protected silver nanoparticle-coated surfaces. Biomaterials. 2012;33(11):3083-3092.

8. He Y, Du Z, Lv H, et al. Green synthesis of silver nanoparticles by Chrysanthemum morifolium Ramat. extract and their application in clinical ultrasound gel. Int J Nanomedicine. 2013;8:1809-1815.

9. Li Y, Leung P, Yao L, et al. Antimicrobial effect of surgical masks coated with nanoparticles. J Hosp Infect. 2006;62(1):58-63.

10. Rai M, Yadav A, Gade A. Silver nanoparticles as a new generation of antimicrobials. Biotechnol Adv. 2009;27(1):76-83.

11. Li WR, Xie XB, Shi QS, et al. Antibacterial effect of silver nanoparticles on Staphylococcus aureus. Biometals. 2011;24(1):135-141.

12. Kim KJ, Sung WS, Moon SK, et al. Antifungal effect of silver nanoparticles on dermatophytes. J Microbiol Biotechnol. 2008;18(8): $1482-1484$

13. Rai MK, Deshmukh SD, Ingle AP, et al. Silver nanoparticles: the powerful nanoweapon against multidrug-resistant bacteria. J Appl Microbiol. 2012;112(5):841-852.

14. Shahverdi AR, Fakhimi A, Shahverdi HR, et al. Synthesis and effect of silver nanoparticles on the antibacterial activity of different antibiotics against Staphylococcus aureus and Escherichia coli. Nanomedicine. 2007;3(2):168-171.

15. Sintubin L, De Gusseme B, van der Meeren P, et al. The antibacterial activity of biogenic silver and its mode of action. Appl Microbiol Biotechnol. 2011;91(1):153-162.

16. Fayaz AM, Balaji K, Girilal M, et al. Biogenic synthesis of silver nanoparticles and their synergistic effect with antibiotics: a study against Gram-positive and Gram-negative bacteria. Nanomedicine. 2010;6(1):103-109.

17. Ghosh S, Patil S, Ahire M, et al. Synthesis of silver nanoparticles using Dioscorea bulbifera tuber extract and evaluation of its synergistic potential in combination with antimicrobial agents. Int J Nanomedicine. 2012;7:483-496.

18. Le A-T, Tam LT, Tam PD, et al. Synthesis of oleic acid-stabilized silver nanoparticles and analysis of their antibacterial activity. Mater Sci Eng C. 2010;30(6):910-916.

19. Suber L, Sondi I, Matijevic E, et al. Preparation and the mechanisms of formation of silver particles of different morphologies in homogenous solutions. J Colloid Interface Sci. 2005;288(2):489-495.

20. Song KC, Lee SM, Park TS, et al. Preparation of colloidal silver nanoparticles by chemical reduction method. Korean J Chem Eng. 2009;26(1):153-155.

21. Ghosh S, Patil S, Ahire M, et al. Gnidia glauca flower extract mediated synthesis of gold nanoparticles and evaluation of its chemocatalytic potential. J Nanobiotechnology. 2012;10:17. 
22. Philip D. Mangifera indica leaf-assisted biosynthesis of well-dispersed silver nanoparticles. Spectrochim Acta A Mol Biomol Spectrosc. 2011;78(1):327-331.

23. Ahmad A, Mukherjee P, Senapati P, et al. Extracellular biosynthesis of silver nanoparticles using the fungus Fusarium oxysporum. Colloids Surf B Biointerfaces. 2003;28(4):313-318.

24. Namasivayam SKR, Gnanendra KE, Reepika R. Synthesis of silver nanoparticles by Lactobacillus acidophilus 01 strain and evaluation of its in vitro genomic DNA toxicity. Nano-Micro Lett. 2010;2(3):160-163.

25. Mokhtari N, Daneshpajouh S, Seyedbagheri S, et al. Biological synthesis of very small silver nanoparticles by culture supernatant of Klebsiella pneumoniae: the effects of visible-light irradiation and the liquid mixing process. Mater Res Bull. 2009;44(6):1415-1421.

26. Kumar CG, Mamidyala SK. Extracellular synthesis of silver nanoparticles using culture supernatant of Pseudomonas aeruginosa. Colloids Surf B Biointerfaces. 2011;84(2):462-466.

27. Kalimuthu K, Suresh Babu R, Venkataraman D, Bilal M, Gurunathan S. Biosynthesis of silver nanocrystals by Bacillus licheniformis. Colloids Surf B Biointerfaces. 2008;65(1):150-153.

28. Sriram MI, Kalishwaralal K, Gurunathan S. Biosynthesis of silver and gold nanoparticles using Bacillus licheniformis. Methods Mol Biol. 2012;906:33-43.

29. Gade A, Ingle A, Whiteley C, et al. Mycogenic metal nanoparticles: progress and applications. Biotechnol Lett. 2010;32(5):593-600.

30. Jagtap S, Pardesi KR, Yavankar SP, et al. Production of bioemulsifier from Acinetobacter spp. from human skin of tribal population. Indian J Exp Biol. 2010;48:70-76.

31. Patil JR, Jog NR, Chopade BA. Isolation and characterization of Acinetobacter spp. from upper respiratory tract of healthy humans and demonstration of lectin activity. Indian J Med Microbiol. 2001;19(1):30-35.

32. Chopade BA, Wise PH, Towner KJ. Plasmid transfer and behavior in Acinetobacter calcoaceticus EBF65/65. Microbiology. 1985;131(10): 2805-2811.

33. Dhakephalkar PK, Chopade BA. High levels of multiple metal resistance and its correlation to antibiotic resistance in environmental isolates of Acinetobacter. Bio Metals.1994;7(1):67-74.

34. Sachdev D, Nema P, Dhakephalkar P, et al. Assessment of 16S rRNA gene-based phylogenetic diversity and promising plant growth-promoting traits of Acinetobacter community from the rhizosphere of wheat. Microbiol Res. 2010;165(8):627-638.

35. Pourali P, Baserisalehi M, Afsharnezhad S, et al. The effect of temperature on antibacterial activity of biosynthesized silver nanoparticles. Biometals. 2013;26(1):189-196.

36. Zaki S, El Kady MF, El-Haleem DA. Biosynthesis and structural characterization of silver nanoparticles from bacterial isolates. Mater Res Bull. 2011;46(10):1571-1576.

37. Sahu PK, Iyer PS, Oak AM, et al. Characterization of eDNA from the clinical strain Acinetobacter baumannii AIIMS7 and its role in biofilm formation. ScientificWorldJournal. 2012;2012:973436.

38. Clinical and Laboratory Standards Institute. Performance Standards for Antimicrobial Susceptibility Testing. Seventeenth informational supplement (M100-S17). Wayne, PA: Clinical and Laboratory Standards Institute; 2007.
39. Nath SS, Chakdar D, Gope G. Synthesis of CdS and ZnS quantum dots and their applications in electronics. Nanotrends. 2007;2(3).

40. Link S, El-Sayed MA. Optical properties and ultrafast dynamics of metallic nanocrystals. Annu Rev Phys Chem. 2003;54:331-366.

41. Henglein A. Physicochemical properties of small metal particles in solution: microelectrode reactions, chemisorption, composite metal particles, and the atom-to-metal transition. J Phys Chem B. 1993;97(21): 5457-5471.

42. He R, Qian X, Yin J, et al. Preparation of polychrome silver nanoparticles in different solvents. J Mater Chem. 2002;12:3783-3786.

43. Novak JP, Feldheim DL. Assembly of phenylacetylene bridged silver and gold nanoparticle arrays. J Am Chem Soc. 2000;122:3979-3980.

44. Naik RR, Stringer SJ, Agarwal G, et al. Biomimtic synthesis and patterning of silver nanoparticles. Nat Mater. 2002;1(3):169-172.

45. Ray S, Das AK, Banerjee A. Smart oligopeptide gels: in situ formation and stabilization of gold and silver nanoparticles within supramolecular organogel networks. Chem Commun. 2006;26:2816-2818.

46. Duran N, Marcato PD, Alves OL, et al. Mechanistic aspects of biosynthesis of silver nanoparticles by several Fusarium oxysporum strains. J Nanobiotechnology. 2005;3:8-14.

47. Duran N, Marcato PD, Duran M, et al. Mechanistic aspects in the biogenic synthesis of extracellular metal nanoparticles by peptides, bacteria, fungi and plants. Appl Microbiol Biotechnol. 2011;90(5):1609-1624.

48. Petit C, Lixon P, Pileni MP. In situ synthesis of silver nanocluster in AOT reverse micelles. J Phys Chem. 1993;97(49):12974-12983.

49. Gurunathan S, Kalishwaralal K, Vaidyanathan R, et al. Biosynthesis, purification and characterization of silver nanoparticles using Escherichia coli. Colloids Surf B Biointerfaces. 2009;74(1):328-335.

50. Deshpande LM, Chopade BA. Plasmid mediated silver resistance in Acinetobacter baumannii. Biometals. 1994;7(1):49-56.

51. Shakibaie MR, Dhakephalkar PK, Kapadnis BP, et al. Plasmid mediated silver and antibiotic resistance in Acinetobacter baumannii BL54. Iran J Med Sci. 1998;23:30-36.

52. Cho KH, Park JE, Osaka T, et al. The study of antimicrobial activity and preservative effects of nanosilver ingredient. Electrochim Acta. 2005;51(5):956-960.

53. Panyala NR, Pena-Mendez EM, Havel J. Silver or silver nanoparticles: a hazardous threat to the environment and human health? JAppl Biomed. 2008;6:117-129.

54. Martinez-Castanon GA, Nino-Martinez N, Martinez-Gutierrez F, Martinez-Mendoza JR, Ruiz F. Synthesis and antibacterial activity of silver nanoparticles with different sizes. J Nanopart Res. 2008;10: 1343-1348.

55. Ansari MA, Khan HM, Khan AA, et al. Evaluation of antibacterial activity of silver nanoparticles against MSSA and MSRA on isolates from skin infections. Biol Med. 2011;3(2):141-146.

56. Guzman M, Dille J, Godet S. Synthesis and antibacterial activity of silver nanoparticles against Gram-positive and Gram-negative bacteria. Nanomedicine. 2012;8(1):37-45.

57. Fontana R, Amalfitano G, Rossi L, et al. Mechanisms of resistance to growth inhibition and killing by $\beta$-lactam antibiotics in enterococci. Clin Infect Dis. 1992;15(3):486-489.

58. Morones JR, Elechiguerra JL, Camacho A, et al. The bactericidal effect of silver nanoparticles. Nanotechnology. 2005;16(10):2346-2353. 


\section{Supplementary tables}

Table SI Zone of inhibition obtained with different concentrations of AgNPs against pathogenic microorganisms

\begin{tabular}{|c|c|c|c|c|c|c|c|c|}
\hline \multirow{3}{*}{$\begin{array}{l}\text { AgNP } \\
(\mu g / d i s c)\end{array}$} & \multicolumn{8}{|c|}{ Zone of inhibition ( $\mathrm{mm})$} \\
\hline & $\begin{array}{l}\text { Acinetobacter } \\
\text { baumannii } \\
\text { AlIMS }\end{array}$ & $\begin{array}{l}\text { Enterobacter } \\
\text { aerogenes } \\
\text { NCIM }\end{array}$ & $\begin{array}{l}\text { Escherichia } \\
\text { coli } \\
\text { ATCC }\end{array}$ & $\begin{array}{l}\text { Pseudomonas } \\
\text { aeruginosa } \\
\text { NCIM }\end{array}$ & $\begin{array}{l}\text { Shigella } \\
\text { sonnie } \\
\text { MTCC }\end{array}$ & $\begin{array}{l}\text { Salmonella } \\
\text { typhimurium } \\
\text { NCIM }\end{array}$ & $\begin{array}{l}\text { Staphylococcus } \\
\text { aureus } \\
\text { MTCC }\end{array}$ & $\begin{array}{l}\text { Streptococcus } \\
\text { mutans } \\
\text { MTCC }\end{array}$ \\
\hline & 7 & 2964 & 25922 & 5029 & 2957 & 2501 & 3160 & 497 \\
\hline 1,024 & 15 & 12 & 14 & 17 & 14 & 13 & 7 & 12 \\
\hline 512 & 14 & 11 & 12 & 15 & 13 & 11 & $\mathrm{NI}$ & 10 \\
\hline 256 & 12 & 10 & 10 & 14 & 12 & 8 & $\mathrm{NI}$ & 9 \\
\hline 128 & 11 & 9 & 8 & 12 & 10 & $\mathrm{NI}$ & $\mathrm{NI}$ & 8 \\
\hline 64 & 10 & 8 & $\mathrm{NI}$ & 11 & 9 & $\mathrm{NI}$ & $\mathrm{NI}$ & 7 \\
\hline 32 & 7 & $\mathrm{NI}$ & $\mathrm{NI}$ & 10 & 8 & $\mathrm{NI}$ & $\mathrm{NI}$ & $\mathrm{NI}$ \\
\hline 16 & $\mathrm{NI}$ & $\mathrm{NI}$ & $\mathrm{NI}$ & 8 & 7 & $\mathrm{NI}$ & $\mathrm{NI}$ & $\mathrm{NI}$ \\
\hline
\end{tabular}

Note: All experiments were repeated twice, and standard deviations were insignificant.

Abbreviations: $\mathrm{AgNP}$, silver nanoparticle; NI, no inhibition. 


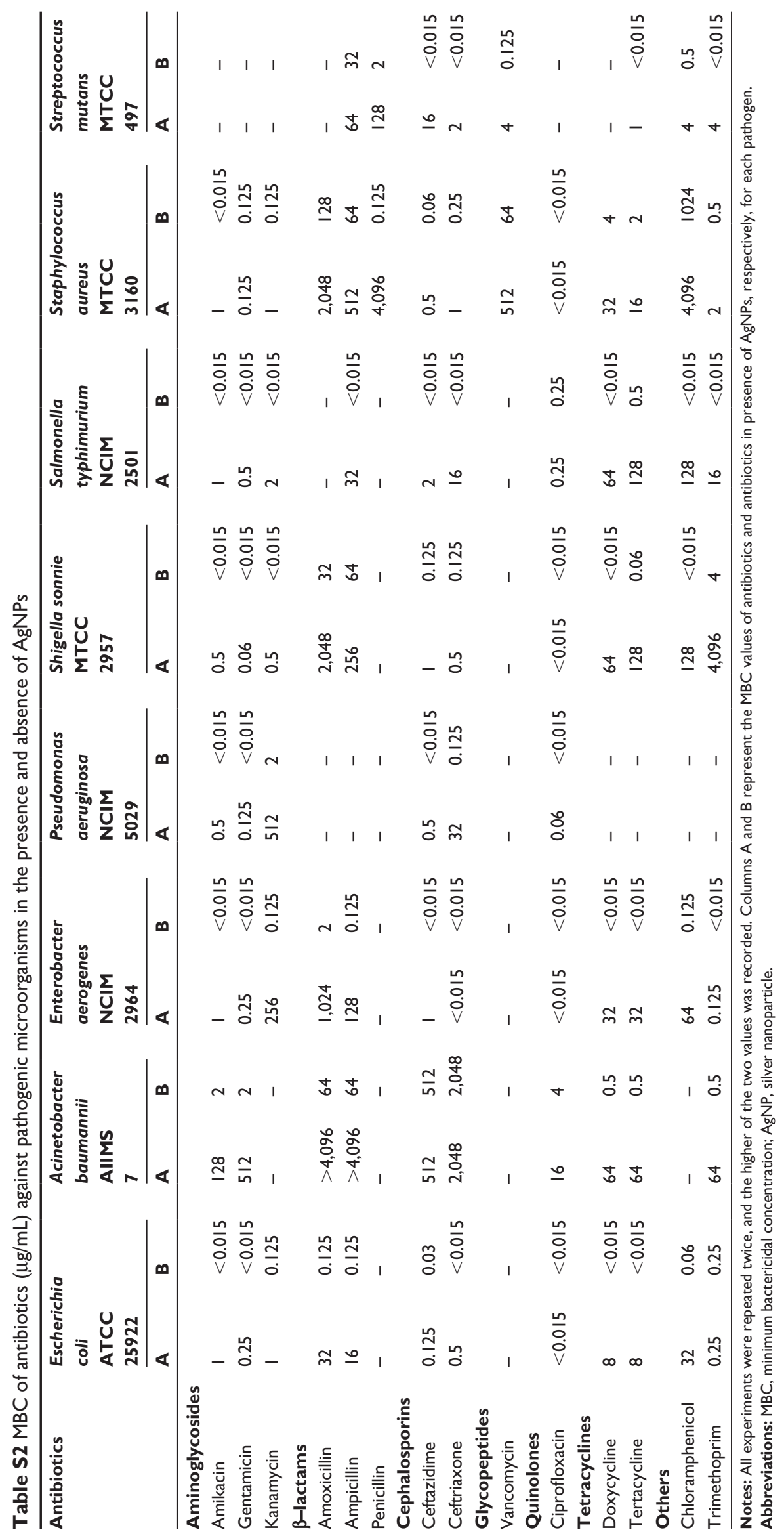




\section{Publish your work in this journal}

The International Journal of Nanomedicine is an international, peerreviewed journal focusing on the application of nanotechnology in diagnostics, therapeutics, and drug delivery systems throughout the biomedical field. This journal is indexed on PubMed Central, MedLine, CAS, SciSearch $\AA$, Current Contents ${ }^{\circledR} /$ Clinical Medicine,
Journal Citation Reports/Science Edition, EMBase, Scopus and the Elsevier Bibliographic databases. The manuscript management system is completely online and includes a very quick and fair peer-review system, which is all easy to use. Visit http://www.dovepress.com/ testimonials.php to read real quotes from published authors.

Submit your manuscript here: http://www.dovepress.com/international-journal-of-nanomedicine-journal 